\title{
Diagnosis of human toxocariasis by antigen capture enzyme linked immunosorbent assay
}

\author{
S H Gillespie, D Bidwell, A Voller, B D Robertson, R M Maizels
}

\begin{abstract}
Aims-To evaluate an antigen capture enzyme linked immunosorbent assay (ELISA) which detects a carbohydrate epitope on the excretory-secretory (ES) antigens of Toxocara canis in clinical practice.

Methods-Serum specimens from healthy adults, patients with acute visceral larva migrans, ocular and inactive toxocariasis, and with other helminth infections were examined by two site antigen capture ELISA.

Results-Over half of the patients (19/28) with acute toxocariasis had a positive result in contrast to a small proportion of those with inactive disease $(1 / 10)$ or ocular infection (2/7). False positive reactions, however, were found in $25 \%$ of the patients with serologically confirmed schistosomiasis and filariasis.

Conclusions-This assay is useful in confirming the diagnosis of acute visceral larva migrans but could not be used alone in diagnosis because of false positive reactions in patients with other helminth infections.
\end{abstract}

(F Clin Pathol 1993;46:551-554)

Toxocara canis is the most important of the parasites causing visceral larva migrans in the human host, ${ }^{1}$ and when a single larva

Division of

Communicable

Diseases, Royal Free

Hospital School of

Medicine, Rowland

Hill St, London NW3

2QG

S H Gillespie

Department of

Clinical Sciences,

London School of

Hygiene and Tropical

Medicine

A Voller

Department of

Biology, Imperial

College of Science,

Technology and

Medicine, London

B D Robertson

R M Maizels

Institute of Zoology, The Zoological Society of London

D S Bidwell

Correspondence to: Dr Gillespie

Accepted for publication 18 December 1992 becomes trapped in the retina the resulting inflammatory response may lead to impaired vision. ${ }^{234}$

Seroprevalence surveys of healthy adults indicate that between $2 \cdot 5 \%$ and $7 \%$ of the adult population have antibodies to Toxocara $s p .^{6}$ In children seroprevalence from $14.6-23 \%$ has been reported in developed countries and up to $84 \%$ where poor sanitation and environmental conditions favour the transmission of geohelminthic parasites..$^{7-10}$

The spectrum of symptoms associated with toxocariasis is diverse and exhibits a wide variation in degree of severity. ${ }^{113}$ Some patients may have eosinophilia and serological evidence of infection in the absence of clinical symptoms and signs. ${ }^{14}$ Others may develop more severe manifestations with fever, bronchospasm, and hepatosplenomegaly. ${ }^{12}{ }^{13}$ Epileptic seizures and myocarditis have also been reported as complications. ${ }^{12}$ The duration of active infection can be prolonged, lasting for more than a year, although duration of symptoms is highly variable. ${ }^{15}$
A complex mixture of glycoprotein antigens is secreted by Toxocara $\mathrm{L}_{2}$ larvae. These antigens contain protease, acetylcholinesterase, and eosinophil stimulating activity. ${ }^{7}$ A strong inflammatory response is made to these antigens and it is thought that the pathological changes associated with acute toxocariasis are due to the consequences of this inflammatory response.

$T$ canis is unable to complete its life-cycle in the human host because larval development is arrested at the $\mathrm{L}_{2}$ stage. This poses diagnostic difficulties as adults do not develop and eggs cannot be found in the faeces. Laboratory diagnosis, therefore, rests on serological techniques. Several different serological methods have been applied to the diagnosis of toxocariasis. ${ }^{16-19}$ An ELISA which detects antibody to the excretory-secretory (ES) antigens is widely used. ${ }^{5}$

We have recently described an antigen capture ELISA which detects a repeating carbohydrate epitope found in the ES antigens of $T$ canis. ${ }^{20}$ This assay was used to follow the natural history of Toxocara infection in animal models and gave positive signals with some but not all of a small range of samples from infected patients. In this study we report the results of a clinical evaluation of this antigen capture sandwich ELISA in acute diagnosis and address the issue of specificity with respect to other widespread helminth infections.

\section{Methods}

Serum specimens were collected from several different groups. Specimens of serum were collected from 108 asymptomatic pregnant women at their booking visit. Specimens were also obtained from those submitted for antiToxocara antibody testing. The presenting symptoms, clinical signs, and laboratory data were recorded using a clinical questionnaire. This, together with the results of an eosinophil count, were used to select 45 patients who were classified as having active or inactive visceral larva migrans, or active and inactive ocular disease.

Forty six serum specimens were also obtained from patients in whom another helminth infection had been diagnosed serologically.

Sixteen serum samples were identified with varying concentrations of antifilarial antibody detected with IgG antibody capture ELISA using Brugia pahangi microfilarial antigen in the solid phase. A further 16 sera with raised 
Table 1 Results of Toxocara canis Tcn-2 antigen detection ELISA in patients with toxocariasis

\begin{tabular}{lllll}
\hline Disease & $N=$ & $\begin{array}{l}\text { Antibody } \\
\text { positive }\end{array}$ & $\begin{array}{l}\text { Antigen } \\
\text { positive }\end{array}$ & Eosinophilia \\
\hline $\begin{array}{l}\text { Acute VLM } \\
\text { (mean age 6.5) }\end{array}$ & 28 & 28 & 19 & 28 \\
$\begin{array}{l}\text { Inactive VLM } \\
\text { (Mean age 24) }\end{array}$ & 10 & 9 & 1 & 2 \\
$\begin{array}{l}\text { Ocular } \\
\text { (Mean age 15.7) }\end{array}$ & 7 & 7 & 2 & 2 \\
\hline
\end{tabular}

VLM: viscera larva migrans.

concentrations of antibody to Schistosoma sp were also identified. Anti-schistosomal antibody concentrations were measured by IgG antibody capture ELISA using Schistosoma mansoni soluble egg antigen in the solid phase. Serum from seven patients with antibodies to Trichinella spirilis and seven with antibodies to Fasciola hepatica, measured by an indirect fluorescence antibody technique, were also included.

\section{IMMUNOASSAYS}

Anti-Toxocara ES antibody ELISA

An ELISA method was used to detect the presence of IgG antibody directed against the ES antigens of Toxocara $\mathrm{sp}$, as reported before. ${ }^{5}$ Briefly, polystyrene microtitration plates were coated with $T$ canis ES antigen derived from in vitro culture at $1 \mu \mathrm{g} / \mathrm{ml}$. A 1 in 200 dilution of patient serum was examined, and the presence of specific IgG antibody binding to ES antigen was detected with a peroxidase labelled mouse anti-human IgG monoclonal antibody. ${ }^{5}$

\section{Monoclonal antibody}

Tcn-2 was selected from a panel of anti-

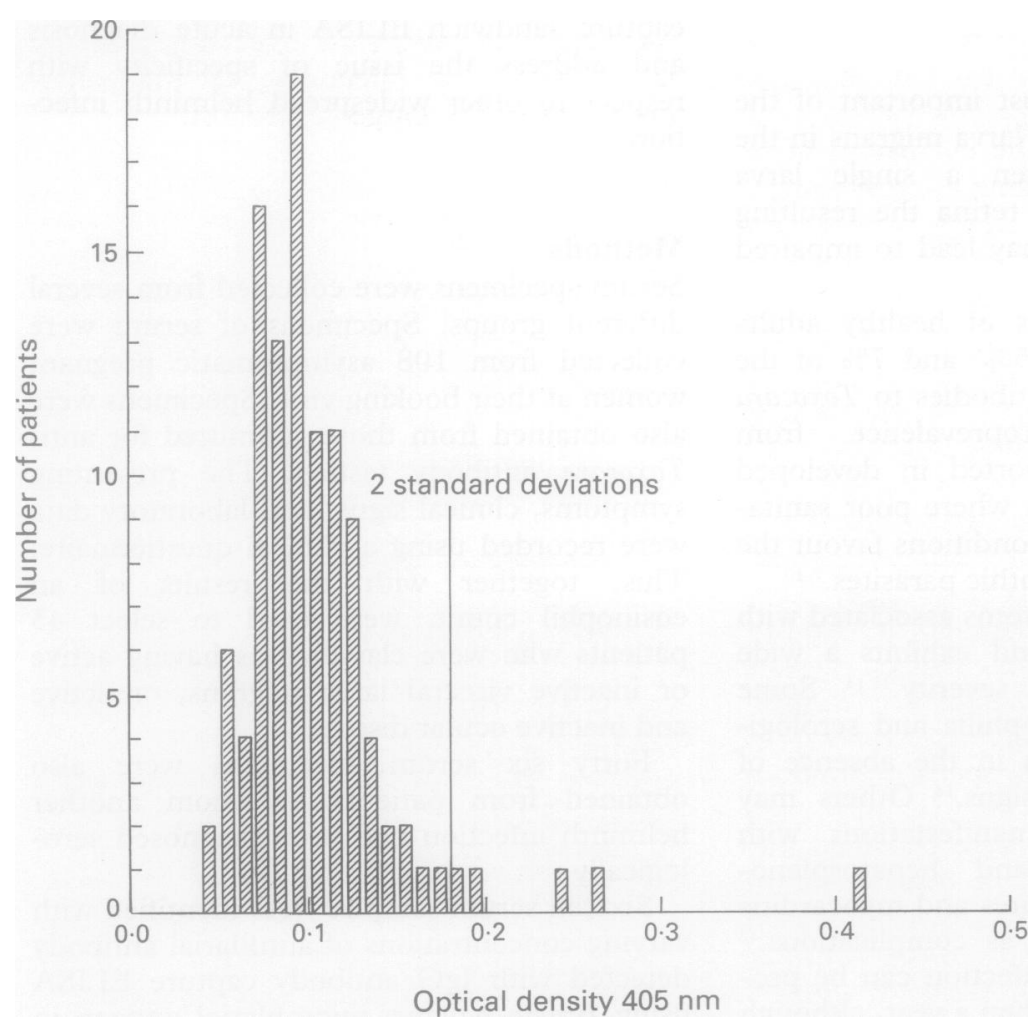

Results of Toxocara canis antigen capture ELISA for 108 antenatal patients.
Toxocara ES monoclonal antibodies because it shows no reaction with other ascarid species. ${ }^{21} 23$ This antibody was purified from ascitic fluid by Sepharose 6 FPLC gel filtration. Tcn-2 antibody was labelled with horse radish peroxidase using the two step glutaraldehyde conjugation method..$^{24}$

\section{Toxocara canis antigen capture ELISA}

A two site antigen capture ELISA was used to detect a repeating polysaccharide epitope present in the ES antigens of $T$ canis. This assay was optimised by checkerboard titration. Polystyrene microtitre plates (Dynatech) were coated with a mouse monoclonal antibody $(1 \mu \mathrm{g} / \mathrm{ml}) \mathrm{Tcn}-2$ by incubation overnight in $0.06 \mathrm{M}$ bicarbonate buffer ( $\mathrm{pH} \mathrm{9.6).}$ They were washed three times with phosphate buffered saline with $0.05 \%$ Tween-20 (PBST) (pH 7.5).

Patient serum was diluted 1 in 25 and incubated for 2 hours at room temperature. The plates were washed again three times with PBST and the presence of captured $T$ canis ES antigen was detected using peroxidase labelled Tcn-2 with hydrogen peroxide and ortho phenylene diamine (Sigma Chemical Co) as substrate. The mean and standard deviation of the negative control population was calculated and a positive result was defined as any serum showing a result greater than 2 standard deviations above the mean.

\section{Results}

Twenty eight of the patients were classified as having acute toxocariasis on the basis of the clinical findings recorded in the questionnaire, the presence of antibodies to the ES antigens of $T$ canis, and more than $0.4 \times$ $10 \%$ eosinophils in the peripheral blood. There were 22 males and six females from the United Kingdom and the Republic of Ireland. The mean age was 6.5 (median 4 ) years. The anti-Toxocara ES ELISA optical density values ranged from $0.27-2.00$ and the eosinophil counts from $0.540 \times 10^{9} / 1$ to $17.0 \times 10^{9} / 1$. Symptoms were varied; four of the patients with eosinophilia were asymptomatic, 10 had mild symptoms, and 14 had classic visceral larva migrans. Ten patients had serological evidence of Toxocara infection: the eosinophil count was within the normal range and there were no symptoms or signs of disease. There were seven cases of ocular toxocariasis, of which four were active and three inactive.

The results are given in table 1. Briefly, over half $(19 / 28)$ of the patients diagnosed as having acute toxocariasis were positive in the antigen assay; only a low proportion of the inactive cases $(1 / 10)$ and patients with ocular toxocariasis patients (2/7) were positive. Among the patients with active toxocariasis there was no correlation between the optical density values obtained in the antibody and antigen detection ELISAs.

Using a cutoff for positivity of 2 standard deviations above the mean, five of the preg- 
Table 2 Results of Toxocara canis Tcn-2 antigen detection ELISA in patients with other helminth infections

\begin{tabular}{llll}
\hline Disease & $N=$ & $\begin{array}{l}\text { Anti-Toxocara } \\
\text { antibody positive }\end{array}$ & $\begin{array}{l}\text { Antigen } \\
\text { positive }\end{array}$ \\
\hline Filariasis & 16 & 1 & 4 \\
Schistosomiasis & 16 & 0 & 4 \\
Trichinosis & 7 & 0 & 2 \\
Fascioliasis & 7 & 1 & 1 \\
\hline
\end{tabular}

nant patients had a positive result, as expected. When the mean plus 3 standard deviations was used, three samples remained clearly positive (figure).

A significant proportion of the patients with other helminth infections were positive in the Toxocara antigen ELISA (table 2).

\section{Discussion}

Toxocariasis is difficult to diagnose, both clinically and in the laboratory. The antigen used in early serological techniques was from adult worm extracts: the bentonite flocculation technique had a specificity of $90 \%$ but low sensitivity. ${ }^{16}$ An indirect haemagglutination test ${ }^{17}$ and complement fixation test ${ }^{18}$ also using adult worm extracts had been described but suffered from a similar lack of specificity due to cross-reaction with other ascarid parasites.

Toxocara canis $\mathrm{L}_{2}$ larvae may be maintained in vitro, and in this state they produce ES antigens. ${ }^{25}$ These antigens have proved a useful reagent in highly specific anti-Toxocara antibody assays using immunofluorescence and ELISA. ${ }^{519}$ Although an ELISA using ES antigen is now established as the standard technique, these assays can not distinguish between active and dormant infection. There are reports of IgE ELISAs but it is not clear from these reports whether these assays provide any advantage over conventional IgG ELISAs. ${ }^{26}$

This study describes the evaluation of an antigen capture ELISA using a mouse monoclonal antibody Tcn-2. This antibody has been shown to be specific for $T$ canis in immunological studies. ${ }^{22}$ It binds to a repeating carbohydrate epitope found on all the major components of the ES antigens. ${ }^{21}$ Animal experiments in non-canid hosts have shown that early in the course of infection ES antigen titres rise rapidly, falling to lower levels once specific antibody is produced..$^{20}$ In canine infection circulating antigen concentrations are at a peak at 4 weeks of age, falling steadily over the first year of life. ${ }^{27}$ It might be expected, therefore, that an antigen capture assay would be useful as a means of diagnosing acute infection, and that the sensitivity of the assay would fall as specific antibody responses developed.

This series of patients were classified into acute or longstanding visceral disease. Of the 28 cases with clinical and laboratory evidence of acute disease, 19 were positive using this assay. The fact that not all were positive might be because a specific antibody response had already developed. In contrast, all but one of the cases of inactive toxocariasis were negative.

We have shown that this assay is of very limited value in cases of ocular toxocariasis: only two of seven cases had a positive antigen result. Both of these cases were unusual in that the specimens were taken at a very early stage of the disease. A sample of vitreous humour was also available for assay in one of these cases and proved strongly positive. Both of these cases are reported in detail elsewhere. $^{3}$ An assay which specifically detected ES antigen would be valuable if applied to vitreous specimens. Vitrectomy has only limited clinical indications, however, so specimens of vitreous are not often available for diagnosis.

Although Tcn-2 has been shown not to bind to the ES antigens of $T$ cati or other closely related parasites, there was a disappointing false positive rate among patients with serological evidence of filariasis, schistosomiasis, trichinosis and fascioliasis. Concomitant toxocariasis could only be considered as an explanation for this phenomenon in one of the patients with filariasis and one with fascioliasis. Such cross-reactions would prove a major disadvantage in the use of this assay in countries where these infections are endemic. In healthy adults tested in this study there was a low false positive rate, but in areas where acute toxocariasis was uncommon even this low rate could be a problem if the antigen detection ELISA was used alone for diagnosis.

Building on the evidence from animal studies we and others have fully reported, investigation of assays which detect Toxocara antigen in immune complexes are required. This may improve the sensitivity of the antigen detection assay system reported here. Such an assay might facilitate study of the natural history of infection, and the pathophysiology of ES antigen excretion.

This work was supported by a grant provided by the North East Thames Regional Health Authority Locally Organised dentship to BDR AV and DB acknowledge the support of the dentship to BDR. AV and DB acknowledge the support of the Overseas Development Administration. We are grateful to $D$ Chiodini (Hospital for Tropical Diseases) for supplying the specimens of serum from patients with helminthic infections. We also thank Phillip Turp and Monica Periera for their technical work.

1 Glickman LT, Schantz PM, Epidemiology and pathogenesis of Toxocariasis. Epidemiol Rev 1981;3:230-50.

Wilder HC. Nematode ophthalmitis. Trans Am Acad Ophthalmol 1950;55:99-109.

3 Dinning WJ, Gillespie SH, Cooling RJ, Maizels RM. Toxocariasis a practical approach to the management of Toxocariasis a practical approach

4 Gillespie SH, Dinning WJ, Voller A, Crowcroft NS. The spectrum of ocular toxocariasis. Eye 1993;7:(in press).

5 de Savigny DH, Voller A, Woodruff AW. Toxocariasis: Serological diagnosis by enzyme immunoassay. $f$ Clin Pathol 1979;32:284-8.

6 Nicholas WL, Stewart AC, Walker JC. Toxocariasis: a serological survey of of blood donors in the Australian Capital territory. Trans Roy Soc Trop Med Hyg 1986;80:217-21.

7 Maizels RM, Robertson BM. Toxocara canis: Secreted glycocongugate antigens in immunobiology and immunodiagnosis. In: Kennedy MW, ed. Parasitic nematodes: diagnosis. In. Kennedy MW, Francis, 1990:95-115.

8 Josephs DS, Bhinder P, Thompson AR. The prevalence of toxocara infection in a child population. Publ Hith (Lond) 1981;95:273-5.

9 Worley G, Green JA, Frothingham TE, et al. Toxocara 
canis infection: clinical and epidemiological associations with seropositivity in kindergarten children. $\mathcal{F}$ Infect Dis with seropositivity

10 Thompson DE, Bundy DAP, Cooper ES, Schantz PM. Epidemiological characteristics of Toxocara canis zoonotic infection of children in a caribbean communiy. Bull WHO 1986;64:283-90.

11 Huntley CC, Costas MC, Lyerly A. Visceral larva migrans syndrome: clinical characteristics and immunological studies. Paediatrics 1965;36:523-36.

12 Glickman LT, Schantz PM, Cypress RH. Epidemiologial characteristics and clinical findings in patients with serologically proven toxocariasis. Trans Roy Soc Trop Med Hyg 1979;73:254-8.

13 Gillespie SH. Human toxocariasis. F Appl Bacteriol 1987; 63:473-9.

14 Bass JL, Mehta KA, Glickman LT, Eppes BM. Clinically inapparent Toxocara canis infection in children. $N$ Engl f Med 1983;308:723-4.

15 Beaver PC, Snyder CH, Carrera GM, Dent JH, Lafferty JW. Chronic eosinophilia due to visceral larva migrans. Pediatrics 1952;9:7-19.

16 Sadun EH, Norman L, Allain D. The detection of antibodies to infections with the nematode Toxocara canis, a causitive agent of visceral larva migrans. $A m \mathcal{7}$ Trop Med Hyg 1957;6:562-8.

17 Jung, RC, Pacheco G. Use of a haemagglutination test in visceral larva migrans. Am $\mathcal{F}$ Trop Med Hyg 1960;9: visceral

18 Fernando ST. Immunological response of the hosts to Toxocara canis (Werner 1782) infection. Parasitol 1968;58:547-59.

19 de Savigny DH, Tizard IR. Toxocaral larva migrans: the use of larval excretory-secretory antigens in haemagglu- tination and soluble antigen fluorescent antibody test. Trans Roy Soc Trop Med Hyg 1977;71:501-7.

20 Robertson BD, Burkot TR, Gillespie SH, Kennedy MW, Wambai Z, Maizels RM. Detection of circulating parasite antigen and specific antibody in experimental Toxocara canis infection. Clin Exp Immunol 1988;74: 236-41.

21 Maizels RM, Kennedy MW, Mejhi M, Robertson BD, Smith HV. Shared carbohydrate epitopes on distinct surface and secreted antigens of the parasitic nemotode Toxocara canis. $\mathcal{F}$ Immunol 1987;139:207-14.

22 Kennedy MK, Maizels RM, Mejhi M, Young L, Qureshi F, Smith HV. Species-specific and common epitopes on the secreted and surface antigens of Toxocara cati and Toxocara canis infective larvae. Parasitol Immunol. 1987; 9:407-20.

23 Page AP, Richards DT, Lewis JW, Omar HM, Maizels RM. Comparison of isolates and species of Toxocara and Toxascaris by biosynthetic labelling of somatic and ES proteins from infective larvae. Parasitology 1991; 103:451-64.

24 Avrameas $S$, Terynck T. Peroxidase labelled antibody and Fab conjugates with enhanced intracellular penetration Immunochemistry 1971;8:1175-9.

25 de Savigny DH. In vitro maintenance of Toxocara canis larvae and a simple method for the production of Toxora ES antigen for use in serodiagnostic tests for visceral larva migrans. $f$ Parasitol 1975;61:781-2.

26 Brunello F, Genchi C, Falaghini P. Detection of larval specific IgE in human toxocariasis. Trans Roy Soc Trop Med Hyg 1983;77:279-80.

27 Matsumura K, Kazuta Y, Endo R, Tanaka K. Detection of circulating toxocaral antigens by sandwich immunoassay. Immunology 1984;51:609-13. 